\title{
Editorial: \\ Is the editor my peer?
}

\section{Akhlesh Lakhtakia \\ Editor-in-Chief}

You write a manuscript that you think breaks new ground on a techno-scientifically important topic. You submit the manuscript to a well-known peer-reviewed journal. Within 10 days, you receive a letter of rejection. The manuscript was neither grammatically deficient nor poorly organized; to your knowledge, it reported original results. But, it had not been sent out for review by even one of your peers. Rejecting it, an editor had written a platitudinous letter to inform you of his/her decision. You ask yourself: Is that editor my peer?

Last week I examined the research credentials of the 18 editors of four highly cited journals publishing peer-reviewed research papers. All 12 gentlemen and six ladies hold doctorates in physics or related disciplines from major universities, which means that all had acquired some research experience. All four journals are focused on topics that are also covered in the Journal of Nanophotonics.

I sought data on the research publications of these 18 editors on Thomson Reuter's Web of Science. Three editors have common enough names that I was unable to easily distinguish their publications from those of others with the same initials and last names. Securitized data for the remaining 15 are presented in Table 1. The journals are identified as J1 to J4.

Table 1. Publication statistics of editors of four highly cited, peer-reviewed, and specialized journals. The names of the journals and the editors have not been identified here to protect their privacy. An asterisk indicates that the name of that editor is shared with such a large number of published researchers that data for him or her could not be isolated easily.

\begin{tabular}{|c|c|c|c|c|}
\hline Journal & Editor & $\begin{array}{c}\text { Number of } \\
\text { Published Items }\end{array}$ & $\begin{array}{c}\text { Number of } \\
\text { Citations }\end{array}$ & $h$ Index \\
\hline J1 & E11 & 24 & 112 & 2 \\
\hline & E12 & $*$ & 1 & 1 \\
\hline & E13 & 6 & 0 & 0 \\
\hline J2 & E14 & 1 & 263 & 6 \\
\hline & E21 & 13 & 769 & 9 \\
\hline & E22 & 43 & 124 & 5 \\
\hline & E23 & 35 & 461 & 12 \\
\hline & E24 & 43 & 206 & $*$ \\
\hline & E31 & $*$ & 12 & 2 \\
\hline & E32 & 17 & $*$ & 10 \\
\hline & E33 & 22 & 273 & 9 \\
\hline & E34 & $*$ & 406 & 12 \\
\hline & E35 & 57 & 530 & 8 \\
\hline & E41 & 17 & 180 & 4 \\
\hline & E42 & 65 & 0 & 0 \\
\hline
\end{tabular}


I also collected similar data for another specialized journal that covers the same topics as the journals $\mathrm{J} 1$ to $\mathrm{J} 4$. This peer-reviewed journal is published by a learned society. It has 17 editors. The anonymous data are presented in Table 2, with the journal's name replaced by the code J5.

Table 2. Publication statistics of editors of a specialized journal published by a learned society. The names of the journal and its editors have not been identified here to protect their privacy. An asterisk indicates that the name of that editor is shared with such a large number of published researchers that data for him or her could not be isolated easily.

\begin{tabular}{|c|c|c|c|c|}
\hline Journal & Editor & $\begin{array}{c}\text { Number of } \\
\text { Published Items }\end{array}$ & Number of Citations & $h$ Index \\
\hline J5 & E51 & 67 & 584 & 14 \\
\hline & E52 & 98 & 935 & 17 \\
\hline & E53 & 128 & 1983 & 23 \\
\hline & E54 & 659 & 7167 & 34 \\
\hline & E55 & 137 & 1710 & 20 \\
\hline & E56 & 30 & 320 & 10 \\
\hline & E57 & 79 & 2659 & 21 \\
\hline & E58 & 145 & 1809 & 14 \\
\hline & E59 & 71 & 681 & 22 \\
\hline & E510 & 56 & 2177 & 13 \\
\hline & E511 & 65 & 568 & 26 \\
\hline & E512 & $*$ & 2008 & 12 \\
\hline & E513 & 114 & 632 & 10 \\
\hline & E514 & 45 & 325 & 25 \\
\hline & E515 & 47 & 263 & 1770 \\
\hline
\end{tabular}

All five journals began publication during the present decade. Let me add that, collectively, most of the publications of the editors of the journals J1 to J4 do not report their authors' research, but the vast majority of the publications of every editor of the journal J5 do.

Whereas the editors of the journal J5 are indeed your peers with credentials vetted by the elected office-bearers of a learned society, and some may have much greater seniority in the research arena than you, comparison of the data in the two tables would help you decide if the editors of the journals J1 to J4 are also your peers. Although every research paper published in those journals is peer-reviewed, would you still call journals J1 to J4 peer-reviewed? 